\title{
Práticas educativas e curriculares na Educação Infantil: currículo posto e currículo praticado
}

\author{
Educational practices and curricular in children education: post curriculum and \\ practiced curriculum
}

Fabrício Oliveira da Silva

Doutor em Educação pela Universidade do Estado da Bahia - UNEB. Professor adjunto da Universidade Estadual de Feira de Santana - UEFS, lotado no Departamento de Educação. Professor permanente do Mestrado em Educação - PGE da Universidade Estadual de Feira de Santana. Coordenador do Núcleo de Estudos e Pesquisa sobre Pedagogia Universitária - NEPPU e

Membro do Grupo de pesquisa Docência, Narrativas e Diversidade na Educação Básica DIVERSO do Programa de Pós-Graduação em Educação e Contemporaneidade - PPGEduC -

UNEB - Bahía, Brasil. fosilva@uefs.br

Lilian Maria de Almeida

Especialista em Educação Infantil pela Universidade do Estado da Bahia - UNEB. Professora da Rede Municipal de Educação de Morro do Chapéu - Bahia, Brasil. prolilianalmeida@htomail.com

Tarcyo Miranda Alves

Especialista em Educação Infantil pela Universidade do Estado da Bahia - UNEB. Professora da Rede Municipal de Educação de Morro do Chapéu - Bahia, Brasil. tarcyomi@hotmail.com

\begin{abstract}
Resumo: $\mathrm{O}$ artigo trata das práticas educativas e curriculares de professores que atuam na Educação Infantil. Aborda e analisa as implicações das práticas educativas em consonância ao currículo desenvolvido na sala de aula, assim como as aproximações e distâncias dessa prática frente aos documentos oficiais nacionais e municipal. O trabalho tem como objetivo identificar as práticas educativas e curriculares desenvolvidas pelas professoras da Educação Infantil no que tange às ações do cotidiano da sala de aula. Elegeu-se como método a abordagem (auto)biográfica, por possibilitar a revelação dos sentidos que as professoras constroem quando narram e refletem sobre sua trajetória de vida, formação e atuação profissional. O trabalho permitiu perceber que muitas vivências da sala de aula estão fundamentadas no documento curricular da rede. Conclui-se que as práticas educativas precisam ser repensadas para acolher as inovações curriculares atuais, assim como repensar e (re)elaborar os planos de ensino e os planos de aula.
\end{abstract}

Palavras chave: Currículo. Educação Infantil. Prática educativa.

Abstract: The article deals with the educational and curricular practices of teachers who work in Early Childhood Education. It addresses and analyzes the implications of educational practices in line with the curriculum developed in the classroom, as well as the approximations and distances of this 
practice in relation to official national and municipal documents. The objective of this study is to identify the educational and curricular practices developed by the teachers of Early Childhood Education in relation to the daily actions of the classroom. The (auto) biographical approach was chosen as a method, because it allows the revelation of the senses that the teachers construct when they narrate and reflect on their life trajectory, formation and professional performance. The work allowed to realize that many classroom experiences are based on the curricular document of the network. It is concluded that educational practices need to be rethought to accommodate current curricular innovations, as well as to rethink and (re) elaborate teaching plans and lesson plans.

Keywords: Curriculum. Child education. Educational practice.

\section{Introdução}

O trabalho do professor de Educação Infatil, como de qualquer professor que atua nas diferentes etapas de escolarização, é marcado por movimentos experienciais e relacionais que se constituem a partir das vivências logradas no cotidiano escolar, logo das práticas educativas que são produzidas em razão de seu ofício. A esse contexto, são transversais a formação dos professores, o currículo enquanto potencializador e estruturante das tessituras de saberes pedagógicos, e a disposição para aprender e desenvolver novos saberes no/pelo movimento da cotidianidade da docência.

Permeado por essa reflexão introdutória, o presente trabalho tem por finalidade a compreensão das distâncias e aproximações entre o currículo formal que está posto nas diretrizes curriculares de uma determinada rede municipal, especialmente para turmas de préescola, e o currículo que de fato é praticado nessas turmas, considerando as práticas educativas e curriculares à luz das narrativas de duas professoras ${ }^{i}$ que lecionam no Pré I e Pré II. Por práticas educativas denominamos as ações que os professores desenvolvem a partir de suas vivências e experiências logradas no cotidiano da sala de aula, estando no bojo das práticas, a inventividade e as adequações que os docentes fazem para ensinar, sobretudo por estarem inseridos contextos específicos das realidades educacionais em que atuam. Já por práticas curriculares, denominamos aquelas que são fruto de ações previstas e postas nas diretrizes curriculares, sejam nacionais ou municipais. Neste entendimento, uma implica na outra, mas se diferenciam pela singularidade das ações que os professores desenvolvem ao se colocarem ativamente no processo de produção e criação de estratégias que criam para ensinar na Educação Infantil.

Sabe-se que aquilo que é praticado pelos sujeitos tem muito a ver com as suas histórias de vida e formação e que ninguém fala melhor de si e de suas práticas que os próprios sujeitos. Por essa compreensão, visualizamos na abordagem (auto)biográfica uma 
possibilidade de adentrar nas histórias de vida, formação e atuação profissional de duas professoras que participaram desse estudo. Utilizamos como dispositivo de coleta de informações as entrevistas narrativas, com o intuito de revelar características do currículo que está sendo praticado, compreendendo até que ponto o que está posto considera o que está sendo praticado e vice e versa.

Neste cenário, o presente trabalho objetiva identificar nas narrativas das professoras as práticas educativas e curriculares desenvolvidas por elas ao atuarem cotidianamente no contexto da Educação Infantil, com o desafio de atender às legislações, mas ao mesmo tempo, com o desafio de serem inventivas e poderem criar e desenvolver práticas que emerjam de suas experiências no trabalho com crianças em uma determinada realidade local. Tomamos um município em específico, pela relação que se estabelece com práticas e estudos dos autores com essa localidade. Ademais por ser um município que apresenta particularidades no trato às orientações curriculares para a Educação Infantil, devido a sua própria história e pioneirismo em investir na qualidade dessa etapa de ensino.

O trabalho de desenvolve a partir de algumas questões problematizadoras que não serão, diretamente, respondidas, mas que são transversais nesse trabalho, evidenciando modos de compreensão e ações que as professoras realizam no cotidiano de suas práticas educativas. Assim sendo, buscamos nesse artigo refletir sobre: Como as professoras vivenciam as práticas educativas a luz das orientações curriculares nacionais e municipal? As práticas pedagógicas evidenciam aproximações e distanciamentos de ações previstas no currículo posto? De que maneira o currículo posto é praticado e o praticado não é posto?

Ao abordar o tema das práticas educativas desenvolvidas por professores que atuam na Educação Infantil não é possível tratar de forma desarticulada de outras questões de igual relevância, como concepções de infância, teorias de construção de conhecimento, as questões curriculares e constituição do cenário educativo dessa etapa de ensino. Nessa lógica, as práticas voltam-se para uma constituição permanente de ações avaliativas, que os professores desenvolvem de modo reflexivo e experiencial, fazendo fluir o processo de ensino e aprendizagem caracterizado por questões oriundas do cotidiano e das problemáticas relativas à criança. No entanto, neste artigo nos ateremos a refletir sobre algumas questões que ganham centralidade nas narrativas que as professoras fazem, quando falam de si, de sua formação e sobretudo de sua atuação profissional.

\section{Caminhos da pesquisa}


Esta pesquisa se desenvolveu a partir da abordagem do método (auto)biográfico, que é utilizado em diversas pesquisas em educação, e que coloca o sujeito, suas experiências, sua história de vida e de formação em contexto de centralidade significativa de sua própria existência. O sujeito é autor de sua narrativa, de sua forma de pensar. É ele quem constrói os sentidos daquilo que narra e do que pensa sobre si.

Ferraroti (2010), um dos autores que reivindica a autonomia do método (auto)biográfico, atesta que as narrativas biográficas são elementos suficientes para compor uma pesquisa legítima e aponta para a necessidade de uma renovação metodológica. Essa abordagem metodológica correspondeu à exigência de uma necessidade do concreto, para que as pessoas pudessem compreender sua vida cotidiana, suas dificuldades e contradições. Dessa forma, foi considerada a ciência das mediações capaz de traduzir comportamentos individuais ou microssociais. A abordagem (auto)biográfica apresenta-se como uma nova forma de mediação entre as ações e a estrutura, entre as histórias individuais e sociais.

A significativa contribuição da abordagem (auto)biográfica é possibilitar ao sujeito o conhecimento de si, de suas próprias práticas educativas com fundamento em um modelo epistemológico concebido a partir da produção de narrativas que, entre outros papéis, têm a função de reconstruir o momento já vivido, em um outro tempo e dimensão estrutural, que já não é mais a vivida, e sim a narrada. Segundo Josso (2004), a abordagem do método (auto)biográfico assinala um processo de mudança de perspectiva do pesquisador, por meio do apuramento de metodologias de investigação-ação-formação, articuladas à construção de uma história de vida. Além disso, demarca a contribuição de um conhecimento que abrange a formação e a autoformação, elucidando as características de um público específico.

Josso (2004) considera que a abordagem (auto)biográfica se constitui em um meio que o sujeito utiliza para observar um aspecto central das situações educativas, favorecendo uma interrogação das representações do saber-fazer e dos referenciais que servem para descrever e compreender o modo de atuar na docência em seu ambiente natural. Neste sentido, a experiência de ser professor na Educação Infatil configura-se como uma possibilidade de desvelamento de práticas desenvolvidas, que só quem desenvolve é capaz de narrar e de falar de si no contexto da práxis experiencial. Isso significa desenvolver e compreender uma prática educativa que se processa via experiência direta com a realidade educacional posta no cotidiano da profissão, o que permite aos sujeitos refletir sobre como essas vivências foram constituindo práticas curriculares na escola, demarcando um currículo que é praticado e que nem sempre é posto pela legislação. 
A noção de práxis humana é, segundo Ferraroti (2010), a especificidade do método. Essa noção é traduzida pela essência humana no conjunto das relações sociais. Para esse autor, qualquer práxis é reveladora das apropriações que esses sujeitos fazem das relações que vivenciam e, também, das próprias estruturas sociais nas quais estão inseridos. Então, o processo de interiorização e exteriorização evidencia o caráter dinâmico da subjetividade. Nessa perspectiva, ocorre a fusão da subjetividade com estrutura social.

Nesse sentido, reconhecemos que a abordagem (auto)biográfica oferece a possibilidade de revelar os sentidos que as professoras atuantes nas turmas de Pré I e Pré II constroem quando narram e refletem sobre sua trajetória de vida, formação e de atuação profissional, assim como sua atuação na sala de aula da Educação Infantil, deixando transparecer o currículo que de fato está sendo praticado por essas educadoras no seu fazer pedagógico cotidiano. As reflexões desencadeadas pelas narrativas (auto)biográficas, trazidas pelo presente estudo, serviram como importante mecanismo para que o currículo formal que está posto venha ser ressignificado, levando em consideração os sentidos e às apropriações reveladas pelos sujeitos que praticam esse currículo.

Como o tema de investigação trata das aproximações e distanciamentos entre o currículo posto e o currículo praticado na práxis educativa docente, percebemos que a melhor maneira de abordarmos a pesquisa foi a (auto)biográfica, porque, o sujeito pesquisado pode relatar as aproximações e os distanciamentos do seu fazer e de sua experiência, premissa básica do método. São situações como essas, também defendidas por estudiosos desse método, como Josso (2004), Nóvoa e Finger (2010), Souza (2011), Rios (2014), Silva (2017) entre outros, que nos levou a adotar a pesquisa (auto)biográfica como possibilidade de desvelar os sentidos e as práticas curriculares desenvolvidas por professores que atuam na Educação Infantil.

Portanto, percebermos que ao narrar, as professoras revisitaram diferentes momentos significativos de suas vivências, gerando uma amostra das apropriações e significados que estas construíram ao longo do tempo na sua prática pedagógica. Desse modo, as entrevistadas desempenham importante papel na produção e na estruturação do conhecimento pedagógico, evidenciando seu protagonismo na produção de práticas educativas e curriculares. A abordagem metodológica permitiu perceber a importância das práticas que ganham sentido e visibilidade nas narrativas, promovendo uma compreensão de que os professores não são apenas técnicos que executam normas e propõem receitas ou se preocupam apenas em aplicar determinadas teorias na prática pedagógica, mas também, são 
construtores de novos conhecimentos, principalmente advindos da ação das relações estabelecidas e da convivência com os diversos atores dentro e fora da escola.

As entrevistas narrativas têm uma significativa importância por serem apontadas com nível de profundidade maior, porque vão além do esquema pergunta-resposta que caracteriza a maioria das entrevistas. Neste contexto, para o desenvolvimento do presente trabalho, levamos em consideração o fato de que as técnicas das entrevistas narrativas exigem que o pesquisador conheça o ambiente da pesquisa, seu funcionamento, suas configurações, necessitando, para isso, que sejam feitas investigações preliminares, constituídas por imersão no campo e consequente observação. Tendo realizado tais observações, formulamos as questões centrais para pensar o estudo que se desenvolveu por meio de uma entrevista narrativa, que foi gravada e transcrita, e posteriormente, entregue aos colaboradores que leram e fizeram a revisão do que foi narrado, promovendo a autorização para uso das entrevistas na presente pesquisa.

As análises se produziram segundo o modelo proposto por Ricouer (2000), denominado de compreensivo interpretativo. Assim, fizemos a leitura de toda a narrativa, observando os núcleos de sentido, que emergiam das escolhas produzidas pelos sujeitos, no que tange às ações pedagógicas praticadas no cotidiano da docência que desenvolvem. Nesta lógica, é o próprio professor o protagonista, o sujeito que elege fatos, informações e situações que deseja contar e ressignificar num processo perene de construção de sentidos e de produção protagonismo de sua própria história, formação e atuação profissional. Assim, quando rememora as ações desenvolvidas, o sujeito filtra as experiências por intermédio da memória, identificando-as como experiência-referência. Josso (2004, p.40) define essa experiência como [...] acontecimento existencial único e decisivo nas práticas efetivas de uma vida[...], e porque não dizer de uma prática que se singulariza nas experiências de cada professor que lida cotidianamente com as práticas educativas.

\section{Currículo posto e currículo praticado na Educação Infantil}

Afinal o que é o currículo? De acordo com Moreira (2000), o termo currículo é encontrado em registros no século XVII, sempre relacionado com um projeto que controla o ensino-aprendizagem. Desde o começo, currículo envolvia uma ideia de ordem, que regula também a administração escolar. Libâneo (2001) enfatiza que o termo currículo possui vários significados. Em sentido restrito, pode representar o "ato de correr", ou um conjunto de 
disciplina da grade curricular de uma escola. Em sentido mais ampliado, no início do século $\mathrm{XX}$, é identificado, quase sempre, enquanto conjunto de saberes e/ou experiências que os alunos precisam adquirir e/ou vivenciar em sua função ou formação. (LIBÂNEO, 2001)

No entanto, o que queremos defender enquanto ideia de currículo está para além dessa ideia burocratizadora da escolha de temas e ou conteúdos estabelecidos numa grade, onde todos os professores envolvidos no fazer pedagógico definem de forma bastante mecanizada a sua escolha. Essa experiência confirma que: "O currículo não é um corpo neutro, inocente e desinteressado de conhecimento. [...] a seleção que constitui o currículo é o resultado de um processo que reflete os interesses particulares das classes e grupos dominantes". (SILVA, 2011, p. 46)

$\mathrm{Na}$ rede municipal em que o trabalho em tela foi desenvolvido, o currículo da Educação Infantil é espelhado em orientações que estão propostas no Referencial Curricular Nacional para a Educação Infantil - RCNEI (2009) que consideram a aprendizagem a partir de eixos, os quais pelos normativos do projeto pedagógico da rede municipal precisam ser considerados de forma integrada. Assim, os eixos se articulam no currículo como forma de desenvolvimento da criança a partir dos princípios de movimento, identidade e autonomia, conhecimento de mundo, artes visuais, música, linguagem oral e escrita, natureza/sociedade e matemática. Do ponto de vista nacional, bem como o que é praticado e legislado na rede municipal, o RCNEI se constitui no âmbito das diretrizes como o objetivo de orientar o planejamento curricular das escolas. Propõe a organização por eixos de interações e brincadeira. Além disso, traz como marco conceitual a indissociabilidade entre o cuidar e educar.

O que se quer de ideia de currículo é a expressão viva das vivências do espaço educativo, na expressão mais singular da formação dos indivíduos no seu tempo e espaço, sendo vistos como autores e construtores de sua história. Para isso, deve ser repensado os diferentes papeis dos distintos educadores da escola.

Nessa perspectiva, nos identificamos com a ideia de que:

$$
\begin{aligned}
& \text { [...] o currículo é o lugar, espaço, território. O currículo é a relação de poder. } \\
& \text { Currículo é trajetória, viagem, percurso. O currículo é autobiografia, curriculum } \\
& \text { vitae: no currículo se forja nossa identidade. O currículo é texto, discurso, } \\
& \text { documento. O currículo é documento de identidade. (SILVA, 2011, p.150) }
\end{aligned}
$$

Uma vez que o currículo pode ser entendido como um campo de interação entre práticas e ideias, Sacristan (2007), salienta que ensinar não é uma atividade meramente instrumental, que coloca em prática um projeto curricular com objetivos e conteúdos previamente estabelecidos. Por isso, o entendimento de currículo não se limita a escolha e a 
definição de expectativas de aprendizagem e instrumentos de avaliação, mas ao movimento contínuo e vivido nos espaços educativos, fato que gera a condição de que os professores produzam a partir de suas próprias vivências e experiências outras dimensões acerca dos sentidos que se atribuem ao currículo, gerando um currículo que é praticado e que nem sempre está posto na legislação. São as crianças, o contexto escolar e o cotidiano das relações que produzem distintas acepções e práticas curriculares.

Como disse Malaguzzi (2001), é necessário seguir as crianças e não os planos. São as crianças, em suas brincadeiras e investigações, que nos apontam os caminhos, as questões, os temas e os conhecimentos de distintas ordens que podem ser por elas compreendidos e compartilhados no coletivo.

O professor, grande articulador, com seu olhar de quem está com a criança, mas também com os saberes e conhecimentos, realiza a complexa tarefa educacional de possibilitar encontros, de favorecer interações lúdicas, constituir tempos e espaços para a experiência das crianças, promovendo um currículo que se dinamiza e se potencializa nas relações cotidianas da escola. Assim, os professores concebem e produzem um sentido de currículo que se caracteriza a partir de toda uma movimentação cultural entre a escola e a comunidade. Por isso, o respeito ao local, ao diverso, ao regional, à história de vida dos sujeitos, à pertinência racial e social, ao gênero, ao não formal, ao não explicitado, deve ser levado em consideração, e devem, portanto, figurar na base da produção curricular que se pratica para além do quer está posto.

Nessa direção, Silva (2011) defende uma concepção curricular ao se questionar sobre:

\begin{abstract}
[...] Qual nossa aposta, qual é o nosso lado, nesse jogo? O que vamos produzir no currículo entendido como prática cultural? Os significados e sentidos, as representações que os grupos dominantes fazem de si e dos outros, as identidades hegemônicas? Vamos fazer do currículo um campo fechado, impermeável à produção de significados e de identidades alternativas? Será nosso papel o de conter a produtividade das práticas de significação que formam o currículo? Ou vamos fazer do currículo um campo aberto que ele é, um campo de disseminação de sentido, um campo de polissemia, de produção de identidades voltados para o questionamento e a crítica? Evidentemente, a resposta é uma decisão moral, ética, política de cada um/uma de nós. Temos de saber, entretanto, que o resultado do jogo depende da decisão de tomarmos partido. $\mathrm{O}$ currículo é, sempre e desde já, um empreendimento ético, um empreendimento político. Não há como evitá-lo. (SILVA, 2011, p. 29)
\end{abstract}

Elaborar currículo para crianças pequenas exige estar inserido numa sociedade, pensando num projeto de formação do ser social, intencionado de ideologias políticas, culturais, que influenciam a vida das crianças, das famílias, das práticas sociais e culturais, na 
garantia do direito a aprender. O currículo deve estar situado no encaminhamento para a experiência não na perspectiva do seu resultado. Sobretudo naquele que contenha referências para novas experiências, para a busca do sentido e do significado, que considera a dinâmica da sensibilidade do corpo, da observação, da constituição de relações de pertencimento, da imaginação, da ludicidade, da alegria, da beleza, do raciocínio e do cuidado consigo e com o mundo.

O currículo é um documento bastante flexível, e essa ideia é percebida quando a professora aborda sua experiência vivida no chão da escola,

\begin{abstract}
[...] eu tinha planejado uma atividade de matemática, de numerais com os meninos. Eu tinha um jogo, levei o jogo. Então um aluno, ele pegou uma abelha, e colocou dentro de um vaso de refrigerante. No intervalo, porque lá tem de tudo, na hora do intervalo. E ele chegou, oh minha abelha! Menino você pegou? Peguei, quando voltou pra sala de aula, o que eu tinha planejado, eu tive de falar agora sobre a abelha. Aí foi músicas de abelha. Pró, você procura aí pró as informações, que eu tenho uma aluna bem falante, procura aí pró, o que acontece? Eu fui explicar tudo de abelha, e a minha aula planejada não foi o que eu tinha planejado que era um jogo, voltou para a abelha. [...] No outro dia, levei outro texto para eles. Ah! você lembrou pró da abelha de ontem? E esse menino levou a abelha pra casa, e a mãe ficou: - Pró você acredita que a abelha morreu e ele começou a chorar? Que a pró contou a história da abelha e minha abelha morreu. Então, às vezes a gente planeja uma coisa, e quando chega lá os meninos fazem a gente mudar completamente o plano. [...] (Marcela, Extrato de narrativa, 2018).
\end{abstract}

É percebível, nesse trecho da narrativa, que planejamento não é algo do professor, mas sim a favor do aluno e da turma, das experiências vividas no dia-a-dia da escola, das crianças que se manifestam e tentam expressar o que desperta a sua curiosidade. Vê-se nesse momento uma relação entre o currículo posto, mas que sofre interferência do praticado que demanda o atendimento da necessidade cotidiana da escola. Mas ao mesmo tempo, há uma aproximação entre o que é posto, a exemplo do que preconiza o RCNEI (2009) ao indicar a necessidade de trabalhar o campo experiencial a partir dos princípios de movimento, identidade e autonomia, conhecimento de mundo. E isso é o que faz a professora, ao lançar mão do contexto que emerge pela presença da abelha, para ressignificar suas práticas educativas e desenvolver, de modo singular e pelo viés do cotidiano, a produção de estratégias pedagógicas que ganham sentido e notoriedade pela vivência, que na relação com aquelas específicas crianças, e a partir da específica situação de chagada da abelha, se produz no chão da escola. 
De certo modo, vemos que a prática da professora evidencia uma aproximação com o que preconiza o currículo posto no RCNEI (2009) ao valorizar o princípio da autonomia das crianças na percepção sobre o conhecimento produzido em torno da abelha, da produção identitária sobre o animal e sua relevância social. Isso implica em validar um conhecimento experiencial que emerge do cotidiano local, das experiências que valorizam os saberes, a curiosidade e a inventividade das crianças. Assim, o currículo posto é praticado pela produção e valorização do campo experiencial e conhecimento de mundo que a criança vai produzindo, movida pela curiosidade e inventividade. Mas no currículo não está posto o modo como a professora produz sua prática educativa contemplando o que ocorre no cotidiano da escola. Assim, a abelha aparece e muda todo o tom de planejamento e ações da professora, evocando um saber que se produz com as crianças, mas que não é posto pelo currículo, pois as tessituras das práticas educativas se fundamentam e principiam no contexto de cada criança, levando em consideração sua historicidade, curiosidade e inventividade, às quais a escola precisa estar atenta para produzir os movimentos formativos das crianças.

As experiências do professor e do aluno emergem como elementos de reconstituição de um fazer que estava planejado, mas que agora ganha novos contornos e elementos significativos para o desenvolvimento da prática educativa e curricular da professora. Esse sentimento tão intrínseco, entre o sujeito e o aprender, motiva e baliza o planejamento do educador. Como ele não é estático, deve-se adaptar à realidade do dia e das crianças. É perceptível pela narrativa, portanto, a existência de olhar para elas, porque elas sinalizam de diferentes formas a vivência do planejamento, se manifestando o tempo todo, ora se submetendo, se envolvendo, aceitando as propostas, ora resistindo e recusando. Nem sempre elas verbalizam o que precisa ser ressignificado, no entanto, manifestam as mudanças que necessitam ser priorizadas no planejamento dos professores.

Ao narrar o fato, vemos como a docente vai constituindo uma narrativa por meio da qual os elementos experienciais ganham destaque e a tessitura argumentativa dá o contorno e produz sentidos sobre o feito da professora. Há um sentido para o tema que envolve a turma e a criança a partir de uma situação que é narrada pela ótica da docente. É ela quem escolhe a sucessão de eventos e o que é importante para ser dito e evidenciado, trazendo para a cena uma prática educativa que se produz no contexto da situacionalidade cotidiana.

Uma possibilidade, ao iniciar os trabalhos com as crianças, é oportunizar que elas digam o que querem aprender, numa consulta expressa através de desenhos, roda de conversas, elaboração e preparação das fichas diagnósticas. Assim, o currículo praticado se 
efetiva na possibilidade da escuta às crianças com o olhar sensível e observador no espaço educativo. Essa pode ser uma das primeiras ações ao elaborar currículos para as crianças, o que demanda, também, a sagacidade do docente de envolver as famílias nesse processo, para que verbalizem o que querem com a proposta educativa para seus filhos tornando-se uma proposta pedagógica de fato participativa e política. De certo que a narrativa não traz claramente esse elemento, mas é possível inferir que ao dá vasão ao trabalho com a abelha, a professora preocupa-se e desloca o seu plano para atender ao que os estudantes querem e provocam.

Na narrativa de Nélida, ela aborda que a experiência adquirida na autonomia da ação docente é o que qualifica uma execução de um trabalho que permite refletir e fazer um balanço dos resultados alcançados,

\footnotetext{
[...] hoje assim, eu já consigo dizer assim não, oh a proposta é essa, mas eu acho que eu posso ir um pouquinho além com a minha turma a depender do nível que ela esteja, eu posso ir um pouquinho além. Não preciso fazer só isso, eu posso fazer isso e mais isso, então assim, hoje eu consigo, é pegar as orientações que são transmitidas pra gente e transcrever da minha forma, sem seguir à risca o que está pedindo e fazer... Conseguir fazer o meu trabalho dentro do que se pede, do que foi orientado e dentro da minha concepção de sala de aula, de professora com aquela turma naquele momento. (Nélida, Extrato de narrativa, 2018)
}

Essa elaboração revela indicativo de que a docente tem consciência do que já se consegue dosar, produzir com a turma, o que só é possível ao se construir relações educativas que emerjam do cotidiano da prática curricular que transcende o que está posto nos documentos normativo. Tal atitude é a conquista da autonomia adquirida com a experiência. A professora consegue perceber algo essencial no planejamento, não aplicar atividades e/ou propostas sem serem refletidas. O planejamento não é transmissão de propostas, mas uma reflexão do que pode ser constituído e desenvolvido numa prática educativa que se constrói na transversalidade do cotidiano da escola. Aqui vemos mais um elemento narrativo que demonstra haver numa interseccionalidade entre o que é posto no currículo e o que, de fato, é desenvolvido pela professora, que leva em consideração seu saber e sua experiência desenvolvida na reação com o estudante e com o que desenvolve no espaço educativo.

As práticas educativas na Educação Infantil refletem as atividades práticas realizadas pelas professoras de modo sistemático e previsto nas diretrizes, bem como seguem uma sequência cronológica de tempo e prioridades, distribuídas em blocos de atividades dentro da rotina. São essas atividades cotidianas, tais como, de entrada e saída das crianças, 
atividades ligadas aos cuidados, higiene e alimentação; as atividades didáticas: as atividades de registro, desenhos, colagem, histórias, atividades com o nome próprio e os momentos de leitura pelo professor acompanhadas de contação de histórias; as atividades lúdicas: oferecimentos de brinquedos, brincadeiras e jogos; as atividades com músicas: canções para brincar em roda, músicas que acompanham as atividades de rotina e as atividades com histórias: momentos em que as crianças manuseiam livros ou ouvem histórias contadas pelas professoras. Mas há espaço para construção e inserção de outras formas de trabalhar com as crianças, que se ancoram na inventividade das professoras e no conhecimento experiencial que elas vão tecendo ao longo de suas vivências com as crianças e com a realidade educacional em que estão inseridas.

\section{Considerações}

O estudo permitiu perceber que as práticas das professoras em suas salas de aula efetivam-se ancoradas numa inspiração do currículo formal, dos elementos ideológicos e estruturantes, através dos documentos como: Referenciais Curriculares Nacionais para Educação Infantil, as Diretrizes Nacionais para Educação Infantil, Base Nacional Comum Curricular, Referencial Curricular município. Mas também revelou que há práticas que se constituem numa tessitura experiencial das professoras, em que suas vivências mostram a existência de um currículo que é praticado, revelado na inventividade da docência que fazem na Educação Infantil, em que entra em jogo a criança e suas caracterizações e necessidades formativas.

Assim, as professoras vivenciam as práticas a luz das diretrizes que estão postas nos documentos normativos, mas conseguem, a partir daí, criar novos mecanismos de ação educativa que transcendam ao que está posto, valorizando saberes experienciais das crianças que emergem das vivências cotidianas. A curiosidade e o contexto local se insurgem como elementos a serem considerados na ação educativa de uma das professoras colaboradoras. A aula de matemática é transformada e ressignificada pela presença de uma abelha que é trazida por uma criança. Essa ação marca o tom das atividades educativas e faz a experiência mobilizar a curiosidade dos demais, a sensibilidade da professora e o envolvimento da família para estabelecer elos de compreensões sobre o sentido que toda a ação tem para a criança.

A ressignificação e a adaptação de planos e práticas educativas são modos de revelar como o currículo é praticado à luz do que é posto. Isso pode ser feito através das entrevistas 
narrativas, pois foi escutando as colaboradoras que pudemos mensurar as distâncias e aproximações que existem entre esses dois marcos, teórico e prático. As distâncias se revelaram na centralidade da criatividade e inventividade dos professores em adaptar suas práticas educativas mobilizadas pelos contextos locais e de curiosidade das crianças. A análise do currículo formal com o currículo que está sendo praticado foi possível mediante as revelações das práticas vivenciadas no chão da escola, ancoradas na abordagem (auto)biográfica.

O currículo, nesse trabalho, além de estabelecer uma correlação entre os documentos oficiais nacionais e municipal, é compreendido como o elemento norteador que está incluso em todas as variáveis que envolvem o fazer pedagógico e o que acontece no espaço educativo. Como ele é um documento vivo e essencial dentro da escola, ele deve ser sempre reconceitualizado, ressignificado e carregado de concepções do grupo que vivencia esse fazer, e que isso vai mudando de acordo as trajetórias de cada indivíduo. O currículo praticado é uma soma das experiências e percursos formativos, das concepções que os educadores possuem.

Assim, a pesquisa aponta que o currículo que é praticado nas turmas de pré-escola na rede municipal preserva algumas das orientações propostas nos documentos, mas o que é colocado em prática apresenta suas especificidades. As professoras demonstraram que o currículo que praticam, mantém uma relação muito direta com os percursos e processos formativos pelos quais cada uma passou. Marcela, uma das professoras do estudo, nos revelou em sua narrativa, que a sua prática está sustentada pelas aprendizagens que ela construiu nas experiências da docência. Já a professora Nélida revelou que o currículo que é praticado por ela é influenciado pelos processos de aprendizagem que emergem de sua vivência e de sua vontade de criar estratégias e formas de ensino que demandem do contexto específico em que atuam.

\footnotetext{
${ }^{\dagger}$ Mesmo em se tratando de um trabalho da abordagem (auto)biográfica, os nomes das professoras são fictícios em atendimento às normas do comité de ética ao qual essa pesquisa foi submetida e aprovada.
}

\section{Referências}


BRASIL. Ministério da Educação e do Desporto. Secretaria da Educação Fundamental. Referenciais curriculares nacionais para a educação infantil. Documento introdutório. Versão preliminar. Brasília: MEC/SEF, 2009.

FERRAROTTI, Franco. Sobre a autonomia do método biográfico. In: NÓVOA, António; FINGER, Matthias (Orgs.). O método (auto) biográfico e a formação. Lisboa: Ministério da Saúde. Depart. Dos Recursos Humanos da Saúde/Centro de Formação e Aperfeiçoamento Profissional, 2010

JOSSO, Marie-christine. Experiências de vida e formação. 2. ed. Natal: Edufrn, 2004

LIBÂNEO, José Carlos. Organização e gestão da escola: teoria e prática. Goiânia: Editora Alternativa 2001.

MALAGUZZI, L. História, idéias e filosofia básica. In: EDWARDS, et al. As Cem Linguagens da Criança - A abordagem de Reggio Emília na Educação da Primeira Infância. Porto Alegre: Artes Médicas Sul, 2001.

NÓVOA, António; FINGER, Matthias. (Orgs.). O método (auto)biográfico e a formação. Natal: EDUFRN; São Paulo: Paulus, 2010.

MOREIRA, A. F. M. O Campo do currículo no Brasil: os anos noventa. In: CANDAU, V. M. (org.). Didática, currículo e saberes escolares. Rio de Janeiro: DP\&A, p.83-107, 2000.

RICOEUR, Paul. Teoria da interpretação. O discurso e o excesso de significação. Trad. por Artur Moão do original inglês Interpretation Theory: discourse and the surplus of meanig. Lisboa: Edições 70, 2000.

RIOS, Jane A. V. P. Narrativas e memórias da profissão docente no meio rural. In: FONTOURA, H. A.; LELIS, I. A. O. M; CHAVES, I. M. A. (Orgs). Espaços formativos, memórias e narrativas. Curitiba: CRV, 2014. p. 273-287

SACRISTÁN, José Gimeno. O currículo: uma reflexão sobre a prática. 3. ed. Porto Alegre: Artmed, 2007

SILVA. Tomas Tadeu. Documento de identidade: uma introdução as teorias do currículo. 3 ed. Belo horizonte: autêntica. 2011. 156 p.

SILVA, Fabrício Oliveira da. Formação docente no PIBID: Temporalidades, trajetórias e constituição identitária. 2017. (Tese) Doutorado em Educação, - Universidade do Estado da Bahia - UNEB, Salvador, Bahia. 220p.

SOUZA, Elizeu Clementino de. Territórios das escritas do eu: pensar a profissão; narrar a vida. Revista Educação, Pesquisa (auto)biográfica, Experiência e Formação, Porto Alegre, EDIPUCRS, v. 34, n. 2, p. 213-220, 2011. 


\section{Dialogia}

Recebido em: 18 fev. 2019 / Aprovado em: 25 jun. 2019

\section{Cite como}

SILVA, Fabrício Oliveira da; ALMEIDA, Lilian Maria de; ALVES, Tarcyo Miranda. Práticas educativas e curriculares na Educação Infantil: currículo posto e currículo praticado. Dialogia, São Paulo, n. 32, p. 292-306, maio/ago. 2019. Disponível em: https://doi.org/10.5585/Dialogia.n32.11645. 